\title{
Desempenho agronômico de porta-enxertos de macieira da série japonesa JM no Meio-Oeste catarinense
}

\author{
Frederico Denardi1 , Maraisa Crestani Hawerroth² e Marcus Vinícius Kvitschal³
}

\begin{abstract}
Resumo - O cultivo de porta-enxertos de macieira no sul do Brasil passou por renovações desde o início da produção comercial na década de 1970. Em função da adaptação, do potencial produtivo e da qualidade dos frutos, atualmente prevalece o uso da combinação 'Marubakaido' e interenxerto de 'M.9', assim como o 'M.9' e o 'Marubakaido' utilizados isoladamente. O objetivo do trabalho foi identificar opções de porta-enxertos de macieira da série japonesa JM com potencial de uso no sul do Brasil, similares ao ananizante 'M.9'. Foram testados quatro porta-enxertos desta série, enxertados com a copa 'Fuji' e cultivados em Caçador, SC. Com base na área da seção transversal do caule, o 'JM.1', 'JM.7' e o 'JM.8' se equivaleram em vigor ao 'M.9', e o 'JM.2' foi mais vigoroso que 'Marubakaido'/'M.9'. Entre os porta-enxertos JM, o JM.7 apresentou elevada estabilidade e foi o mais produtivo; já o 'JM.2' gerou os frutos de maior massa, e foi o mais estável para esse caráter.
\end{abstract}

Termos para indexação: Malus prunifolia; rebrotamento; burrknots; produção; estabilidade.

\section{Agronomic performance of apple tree rootstocks of Japanese JM series in the Santa Catarina Midwestern}

Abstract - The cultivation of apple rootstocks in southern Brazil is changing since the beginning of commercial production in the 1970s. Due to the adaptation, productive potential and quality of the fruits, currently it is predominating the use of the combination 'Marubakaido' and interstem 'M.9', as well as the use of 'M.9' and the 'Marubakaido' singly. The objective of this work was to identify some apple rootstock options of the Japanese series JM for southern Brazil with similar potential to the dwarfing 'M.9'. It was tested four apple rootstocks of the JM series, grafted with 'Fuji' scion grown in Caçador-SC. Based on the trunk cross-sectional area, the 'JM.1', 'JM.7' and 'JM.8' equaled the vigor of 'M.9', and 'JM.2' was more vigorous than 'Marubakaido'/'M.9'. Among JM rootstocks, the JM.7 showed high stability and was the most productive. The 'JM.2' produced fruits of greater mass among the tested rootstocks, proving to be the most stable for this trait.

Index terms: Malus prunifolia; suckering; burrknots; production; stability.

\section{Introdução}

Desde o início dos cultivos de macieira no sul do Brasil, há aproximadamente 50 anos, têm ocorrido mudanças no contexto da adoção de cultivares copa e também de porta-enxertos. Quanto aos porta-enxertos, a produção de maçãs esteve na maior parte do tempo alicerçada no uso das séries inglesas $\mathrm{M}$ e $\mathrm{MM}$, que foram desenvolvidas para condições edafoclimáticas diferentes das existentes no sul do Brasil (CUMMINS \& ALDWINCKLE, 1983). No transcorrer do tempo esses porta-enxertos passaram a expressar limitações relacionadas à suscetibilidade a doenças e/ ou pragas de solo, características no sul do Brasil (DENARDI et al., 2015). Inicialmente, foi utilizado o semiananizante 'MM.106', cujo vigor se enquadrava meIhor aos sistemas de cultivo da época. Contudo, com o tempo foi verificado elevada mortalidade de plantas causada pela podridão do colo (Phytophthora cactorum), em função da suscetibilidade do 'MM.106' a esse fungo (DENARDI \& SPENGLER, 2001). Substituído pelo 'M.7', de vigor semelhante, porém mais resistente à podridão do colo, este logo evidenciou ataque severo de pulgão lanígero (Eriosoma lanigerum), como também excesso de rebrotes no colo das plantas (DENARDI, 2002). Alternativamente, foi substituído pela combinação dos porta-enxertos Marubakaido (usualmente chamado de Maruba) e 'M.9' como interenxerto ('filtro'), que tem sido utilizado até os dias de hoje.

Essa combinação vem atendendo de forma relativamente satisfatória as demandas do setor produtivo brasileiro quanto ao controle do vigor das plantas, precocidade de frutificação, produtividade, qualidade dos frutos e, acima de tudo, demonstra boa tolerância a doenças de replantio da macieira do 'Maruba'. Além da facilidade de enraizamento por estacas dormentes, o 'Maruba' apresenta resistência simultânea à podridão do colo e ao pulgão lanígero (SOEJIMA et al., 1998a). Contudo, apresenta forte rebrotamento no colo das plantas e, quando o 'filtro' de 'M.9' fica

\footnotetext{
Recebido em 8/4/2020. Aprovado para publicação em 17/6/2020.

Engenheiro-agrônomo, M.Sc. (aposentado), Epagri/ Estação Experimental de Caçador, Rua Abílio Franco n.1500, Bairro Bom Sucesso, Cep. 89501-032, Caçador-SC, e-mail: denardi.frederico@gmail.com

2 Engenheira-agrônoma, Dra., Epagri/Estação Experimental de Caçador, e-mail: maraisahawerroth@epagri.sc.gov.br

3 Engenheiro-agrônomo, Dr., Epagri/ Estação Experimental de Caçador, e-mail: marcusvinicius@epagri.sc.gov.br.
} 
totalmente exposto no plantio, tende a desenvolver muitos burrknots ao longo do caule (DENARDI et al., 2018). Os burrknots são nódulos aéreos de estruturas radiculares que prejudicam a livre circulação de seiva e, por consequência, o desempenho produtivo da copa, e servem de nicho para o desenvolvimento do pulgão lanígero (KÜDELA et al., 2009).

Por outro lado, o 'M.9' tem boa resistência à podridão do colo (CUMMINS \& ALDWINCKLE, 1983), é altamente eficiente na indução da copa à precocidade de frutificação, elevada produtividade e alta qualidade de frutos (WEBSTER, 2002), mas é muito suscetível ao pulgão lanígero (BUS et al., 2008) e induz à copa fraca ramificação em relação a outros porta-enxertos já estudados (DENARDI et al., 2013).

Estudos conduzidos no Japão por Soejima et al. (1998a; 1998b) indicaram que os porta-enxertos da série JM apresentam as características mais relevantes dos seus parentais 'Maruba' var. Seishi e 'M.9', como a indução à precocidade de produção, alta produtividade e boa qualidade dos frutos. Outra qualidade dos porta-enxertos JM é a facilidade de propagação por estacas dormentes, a exemplo do seu parental 'Maruba'. Segundo esses mesmos autores, o 'JM.1', o 'JM.7' e o 'JM.8' apresentam resistência simultânea à podridão do colo e ao pulgão lanígero, que são pragas importantes no Brasil. Por isso, podem representar opções de porta-enxertos interessantes para uso nas condições brasileiras. Logo, o objetivo deste trabaIho foi identificar alternativas de portaenxertos da série JM para o cultivo da macieira no sul do Brasil, portadores de características agronômicas similares às do ananizante 'M.9', associadas à resistência simultânea à podridão do colo e ao pulgão lanígero.

\section{Materiais e métodos}

O experimento foi instalado no inverno de 2003 na Epagri/Estação Experimental de Caçador, em Caçador, $\mathrm{SC}$, em área com relevo levemente ondulado (altitude 960m, 2649'7,86" s; $50^{\circ} 59^{\prime} 12,67^{\prime \prime}$ O), e solo tipo Bruno Húmico Distrófico. A área experimental foi cultivada com macieiras até quatro anos antes da implantação do experimento, com posterior manejo em rotação de culturas, com milho, aveia e, no último ano, com ervilhaca. Visando minimizar os efeitos nocivos das doenças de replantio da macieira e a melhoria da qualidade do solo, os restos culturais foram integralmente incorporados ao solo em cada ano. A análise química do solo indicou a seguinte composição (0 a $40 \mathrm{~cm}$ de profundidade): $\mathrm{M} .0 .=5,3 \% ; \mathrm{P}=<1 \mathrm{mg}$ $\mathrm{L}^{-1} ; \mathrm{K}=108 \mathrm{mg} \mathrm{L}^{-1} ; \mathrm{Ca}=9,7 \mathrm{cmolc} \mathrm{L}^{-1} ; \mathrm{Mg}$ $=4,8 \mathrm{cmolc} \mathrm{L}^{-1} ; \mathrm{Al}=0,0 ; \mathrm{pH}_{\mathrm{H} 2 \mathrm{O}}=6,0$; índice $\mathrm{SMP}=6,1$. Precedente ao plantio, foi realizada a correção da fertilidade do solo aplicando-se $360 \mathrm{~kg} \mathrm{ha}^{-1}$ de $\mathrm{P}_{2} \mathrm{O}_{5}, 120 \mathrm{~kg}$ $\mathrm{ha}^{-1}$ de $\mathrm{K}_{2} \mathrm{O}$, e $5,5 \mathrm{~kg} \mathrm{ha}^{-1}$ de $\mathrm{B}$, incorporados ao solo via subsolagem a $40 \mathrm{~cm}$. No período de experimentação, de 2003 a 2009 , foi constatada a precipitação anual média de $1.365 \mathrm{~mm}$, e médias de 480 horas de frio $\leq 7.2^{\circ} \mathrm{C}$ e 921 unidades de frio, conforme modelo Carolina do Norte Modificado (EBERT et al., 1986), respectivamente.

Foram testados os porta-enxertos JM.1, JM.2, JM.7 e JM.8, da série japonesa JM, em comparação ao desempenho dos tradicionais M.9 (ananizante) e da combinação Marubakaido e interenxerto M.9 (Maruba/M.9). Todos foram enxertados com o cultivar copa Fuji standard. No início e no final de cada fila de plantas, no pomar e entre as parcelas, foi inserida uma planta de 'Galaxy' com intuito de garantir polinização adequada. O delineamento experimental foi em blocos casualizados, com quatro repetições de três plantas por parcela, cultivadas no espaçamento de $4,0 \mathrm{~m}$ entre filas e $1,8 \mathrm{~m}$ entre plantas (1.389 plantas ha-1).

Na ocasião da primeira brotação, na safra 2003/2004, logo após o plantio do pomar, as plantas foram avaliadas mediante a contagem do total de gemas por planta (em unidade) e do número de gemas brotadas (em unidade), com consequente definição da porcentagem de gemas brotadas (em \%). Nesta mesma ocasião, como indicativos indiretos de precocidade de entrada em produ- ção, buscou-se identificar o número médio de flores por planta (em unidade) e o número de plantas por parcela que apresentavam flores (em unidade).

O número de rebrotes dos porta-enxertos no colo das plantas e a emissão de burrknots ao longo do caule dos porta-enxertos foram avaliados ao longo de cinco safras (2004/05 a 2008/09), sendo o valor médio expresso em unidade planta ${ }^{-1}$. Os caracteres produção média anual por planta e a produção acumulada foram obtidos a partir da mensuração da massa de frutos colhidos em cada planta nas safras 2005/06, 2006/07, 2007/08 e 2008/09, expressos em kg

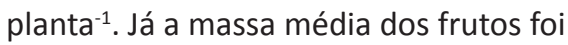
definida pela razão entre a produção e o número de frutos por planta ao longo de quatro safras (2005/06 a 2008/09), expresso em g. O vigor de planta foi definido de forma indireta a partir da aferição da área da seção transversal do caule (ASTC, expressa em $\mathrm{cm}^{2}$ ), avaliada na safra 2008/09. A ASTC foi definida pela mensuração do diâmetro ('d') do caule da copa a $5 \mathrm{~cm}$ acima do ponto de enxertia, medido com auxílio de paquímetro digital, sendo ASTC $\left(\mathrm{cm}^{2}\right)=\pi \mathrm{d}^{2} / 4$. Logo, o caráter eficiência produtiva acumulada foi determinado a partir da relação entre a produção acumulada nas quatro safras de cultivo (2005/06 a 2008/09) e a ASTC medida na safra 2008/09, expresso em $\mathrm{kg} \mathrm{cm}^{-2}$ ASTC.

Visando atender às pressuposições da análise de variância, os dados obtidos para as variáveis total de gemas de flor por planta, precocidade de frutificação, número de rebrotes e número de burrknots por planta, foram transformados utilizando a expressão "raiz quadrada de $x$ somado de 1 unidade, $\left[(x+1)^{1 / 2}\right]^{\prime \prime}$. Foi realizada a análise de variância visando identificar os efeitos dos tratamentos, sendo as comparações entre médias realizada pelo teste ScottKnott $(P>0,05)$.

Para os dados de produção acumulada e ASTC, também foi realizada análise de variância simples e comparações entre médias pelo teste de Scott-Knott $(P>0,05)$. Já para os dados de produtividade anual de frutos e a massa média dos frutos, realizou-se análise de va-» 
riância conjunta em esquema fatorial simples, considerando os fatores portaenxerto e as safras de cultivo. Para as interações significativas, realizou-se o desdobramento dos níveis de cada fator mediante comparações entre médias também pelo teste Scott-Knott $(P>0,05)$.

Para os dados de produtividade de frutos e de massa média de frutos, foram estimados os parâmetros de estabilidade, conforme metodologia proposta por Annicchiarico (1992). Esse método baseia-se no índice de confiança genotípico, estimado pelo modelo $\omega i=\hat{\mu}_{i(g)}-Z_{(1-\alpha)} \hat{\sigma}_{Z 1(g)}$, considerando-se todos os ambientes (safras), em que $\hat{\mu}_{i(g)}$ é a média percentual dos genótipos i; $\hat{\sigma}_{Z 1(g)}$ é o desvio padrão dos valores de $Z_{i i}$, associado ao i-ésimo genótipo; $Z_{(1-\alpha)}$ é o percentil da função de distribuição normal padrão. O coeficiente de confiança adotado foi de $75 \%$, ou seja, $\alpha=0,25$. São consideráveis mais estáveis aqueles genótipos associados aos maiores valores do índice de confiança $\left(\omega_{i}\right)$. Todos os procedimentos estatísticos foram efetuados com auxílio do programa Genes (CRUZ, 2013).

\section{Resultados e discussão}

No primeiro ciclo de brotação, os porta-enxertos JM avaliados não diferiram entre si e em relação ao M.9 e à combinação Maruba/M.9 quanto ao total de gemas por planta e a porcentagem de gemas brotadas. Contudo, em precocidade de frutificação, ao considerar o número de gemas de flores por planta e o número de plantas com flor nas parcelas, os porta-enxertos JM.1 e

Tabela 1. Desempenho da macieira Fuji sobre diferentes porta-enxertos quanto aos efeitos sobre brotação das gemas da copa, caracteres indicadores de precocidade de entrada em produção e caracteres relacionados à planta com o cultivo na Epagri/Estação Experimental de Caçador, em Caçador, SC, Brasil

Table 1. Development of the Fuji apple variety grafted on different rootstocks considering its effects on bud sprouting of scion, characters of early bearing and plant-related characters with the cultivation at Epagri/Caçador Experimental Station, in Caçador, SC, Brazil

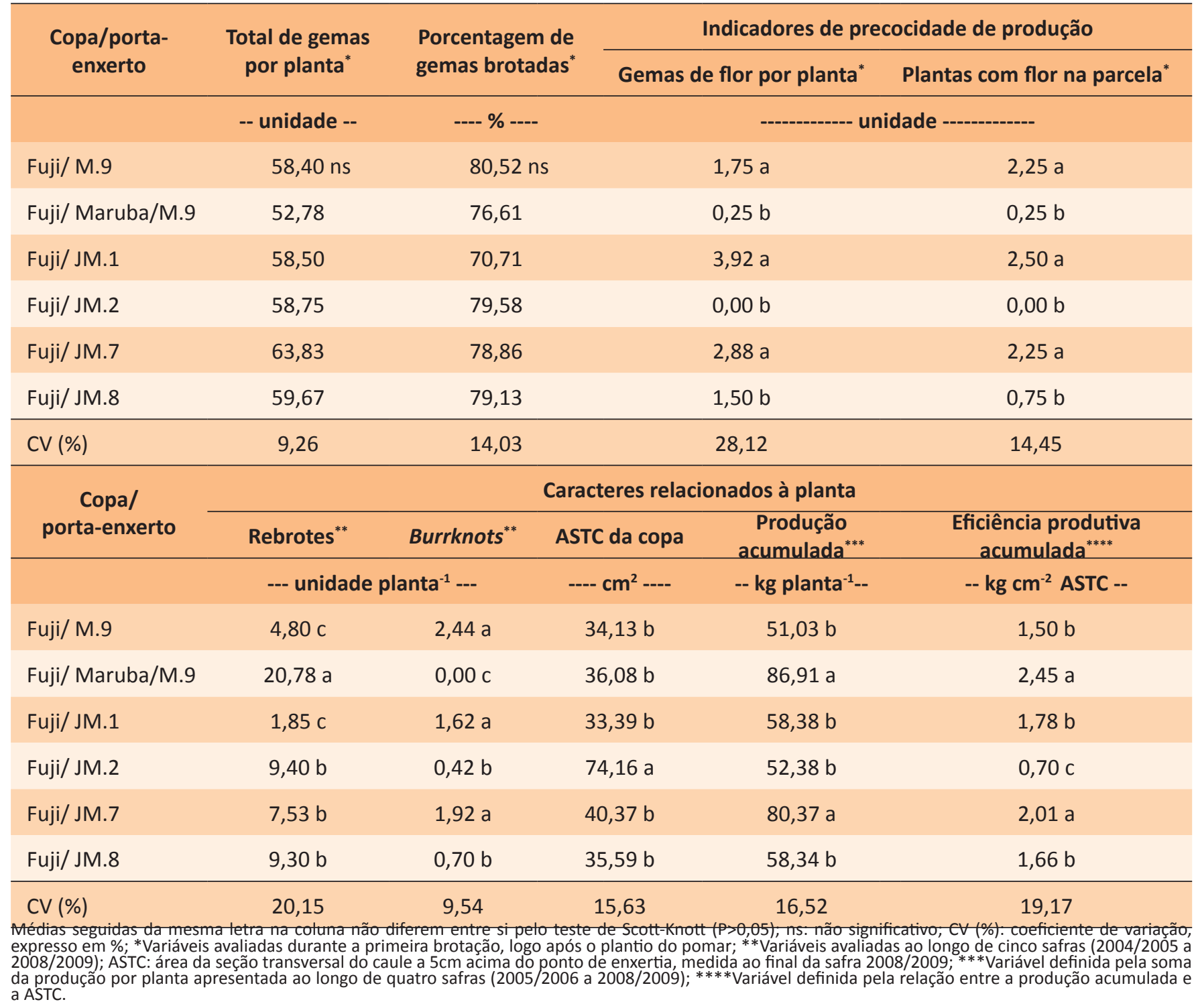


JM.7 foram os mais precoces (Tabela 1), sendo equivalentes ao M.9, que é considerado um bom padrão em induzir precocidade à copa (RUSSO et al., 2007; AUTIO et al., 2011; ROBINSON \& FAZIO, 2011). A precocidade de produção está diretamente relacionada ao tempo de retorno do capital investido com o plantio do pomar e com a produção acumulada ao longo do tempo. Na avaliação conduzida por Soejima et al. (1998a), o 'JM.1', o 'JM.7' e o 'JM.8' induziram à copa de 'Fuji' precocidade de produção similar ao 'M.9'. Em relação ao vigor, definido indiretamente com base na ASTC, observou-se que o 'JM.2' foi o porta-enxerto mais vigoroso (Tabela 1). Embora o M.9 seja considerado um porta-enxerto bastante ananizante e a combinação 'Maruba/M.9' tenda a conferir porte semiananizante à copa (DENARDI et al., 2013; PASA et al., 2016), isso não foi observado nesta avaliação, uma vez que 'M.9' e 'Maruba/M.9' proporcionaram vigores equivalentes às plantas de Fuji (Tabela 1). Neste estudo em particular, a ASTC considerada de forma isolada como indicador do vigor pode não ter conseguido expressar de forma efetiva a diferença entre as combinações copa e porta-enxertos testadas. Neste sentido, ressalta-se a importância da quantificação de variáveis adicionais, de forma conjunta, buscando uma caracterização mais global do vigor das plantas de macieira, como o número de ramos ao longo do líder, crescimento de ramos do ano, volume de material de poda retirado em cada ano, entre outras.

Russo et al. (2007) também observaram vigor similar entre plantas de 'Gala' enxertadas sobre o 'JM.1' e o 'JM.7' em relação ao 'M.9', enquanto o 'JM.2' foi o que induziu vigor significativamente maior. Do mesmo modo, Soejima et al. (1998a) observaram vigores equivalentes de plantas de Fuji enxertadas sobre o 'JM.1', 'JM.7' e 'JM.8' em relação ao 'M.9', enquanto o 'JM.2' também induziu maior vigor. Estes autores relatam que o 'JM.7' e o 'JM.8' manifestaram sobrecrescimento no ponto de enxertia, característica peculiar dos porta-enxertos ananizantes, a exemplo do 'M.9' (DENARDI, 2002). Do mesmo modo, Soejima et al. (1998b) relataram que, entre porta-enxertos da série JM estudados no Japão, o JM. 2 foi o mais vigoroso. Em avaliação conduzida no Brasil, Pasa et al. (2016) observaram vigores similares da copa 'Fuji Mishima' enxertada sobre o 'JM.2' e sobre 'Maruba/M.9'.

A combinação 'Maruba/M.9' evidenciou o maior número de rebrotes formados na região do colo do portaenxerto Maruba, enquanto os menores índices foram apresentados pelo 'JM.1' e pelo 'M.9' (Tabela 1). Diferentemente, Russo et al. (2007) não observaram rebrotes nos porta-enxertos JM.1, JM.2 e JM.7 em ensaios com a cv. Gala nos EUA. Já em relação à formação de burrknots, apenas a combinação 'Maruba/M.9' não manifestou essas estruturas ao longo do caule do porta-enxerto. Os autores Soejima et al. (1998a) enfatizam que essa é uma das principais vantagens do 'Marubakaido' em relação aos portaenxertos ingleses das séries $\mathrm{M}$ e MM. Os porta-enxertos JM.1 e o JM.7 apresentaram o maior número de burrknots no caule, equivalentes ao 'M.9', que é um dos seus parentais e é considerado, inclusive por outros autores, muito propenso à formação de burrknots (AUTIO et al., 2011).

Quanto ao desempenho produtivo, a maior produção acumulada das plantas de 'Fuji' ao longo de quatro safras foi proporcionada pelo porta-enxerto ananizante JM.7, cujo desempenho foi similar ao da combinação 'Maruba/M.9' (80,37 e 86,91 kg planta-1 ${ }^{-1}$, respectivamente). Já os porta-enxertos 'JM.1', 'JM.2' e 'JM.8', por sua vez, foram os que induziram menor produção acumulada, cuja média foi equivalente à do portaenxerto 'M.9'. Russo et al. (2007) e Soejima et al. (1998a) também reportam melhor produção acumulada induzida pelo JM.7, tanto para plantas de 'Gala' quanto de 'Fuji', o que sugere vantagens agronômicas desse porta-enxerto não só nos EUA ou no Japão, mas também no Brasil. Pasa et al. (2016; 2017), em ensaios realizados na região de São Joaquim, não observaram desempenhos produtivos de clones de 'Gala' e 'Fuji' enxertadas sobre o JM.7 tão interessantes quanto aos dos porta-enxertos da série americana Geneva ${ }^{\circ}$. Contudo, isso pode ter se dado em função das condi- ções de solo e clima daquela região, que são muito peculiares pela topografia acidentada, com solos rasos e pedregosos e de menor fertilidade natural.

Outra variável importante a ser considerada é a eficiência produtiva acumulada, que tem sido utilizada para expressar a capacidade de porta-enxertos de macieira em induzir produtividade à copa da planta (ROBINSON et al., 2011; ROBINSON \& FAZIO, 2011). Nesta avaliação, o cv. 'Fuji' mostrou maior eficiência produtiva acumulada quando enxertada sobre o 'JM.7' e sobre a combinação 'Maruba/M.9' (Tabela 1). Os desempenhos apresentados quando enxertada sobre o 'JM.1' e sobre o 'JM.8' foram equivalentes ao observado no 'M.9', enquanto a menor eficiência produtiva acumulada foi observada sobre o portaenxerto 'JM.2', possivelmente justificada pelo seu maior vigor. Contudo, Russo et al. (2007) reportam maiores médias de eficiência produtiva acumulada da 'Gala' quando enxertada sobre 'JM.2' e 'JM.7', sendo até mesmo superiores às medias de alguns clones de 'M.9'. Já Soejima et al. (1998a) observaram maior eficiência produtiva acumulada em plantas de 'Fuji' quando enxertadas sobre o 'JM.7', sendo este porta-enxerto também superior ao efeito do 'M.9 $E M L A$ ', cujo desempenho foi equivalente à adoção dos porta-enxertos 'JM.1' e 'JM.8'.

Ao observar a produtividade anual do cultivar copa Fuji ao longo das safras 2005/06 a 2008/09 (Tabela 2), verificase que os porta-enxertos JM.1, JM.2 e M.9 já atingiram desempenho produtivo mais elevado na terceira safra. Já o JM.8 e a combinação Maruba/M.9 foram os mais tardios quanto à expressão do potencial produtivo da copa 'Fuji', tendo evidenciado as maiores produções expressas no último ano de avaliação.

Em relação à estabilidade de desempenho produtivo induzido pelos diferentes porta-enxertos à 'Fuji' (Tabela 2), observou-se que a combinação 'Maruba/M.9' apresentou a maior regularidade de produção, seguida pelo porta-enxerto 'JM.7', os quais evidenciaram as maiores produções por planta ao longo das quatro safras consideradas. A es-» 
Tabela 2. Comportamento médio para produtividade por planta e massa de frutos apresentado pela macieira Fuji enxertada em diferentes porta-enxertos ao longo de quatro safras de cultivo e análise dos parâmetros de estabilidade ( $\omega^{i}$ ) com base no modelo proposto por Annicchiarico (1992)

Table 2. Mean behavior for yield per tree and fruit mass of the Fuji apple variety grafted on different rootstocks over four seasons and analysis of stability parameters $\left(\omega^{i}\right)$ based on the model proposed by Annicchiarico (1992)

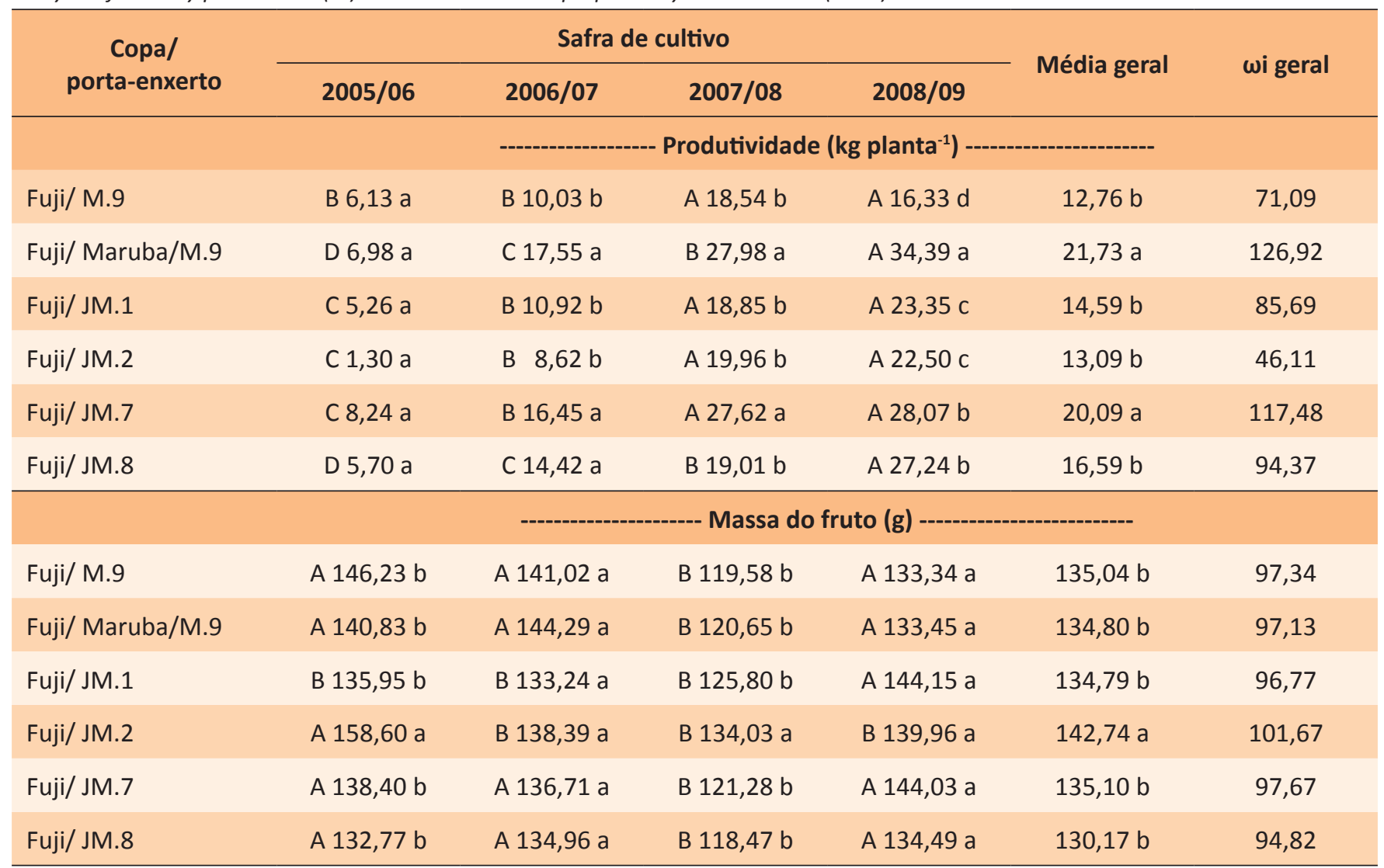

Médias seguidas da mesma letra minúscula na coluna e maiúscula na linha não diferem significativamente entre si pelo teste $S c o t t-K n o t t ~(P>0,05)$.

timativa do índice de confiança $\omega_{i}$ representa a probabilidade estatística de que o i-ésimo porta-enxerto não irá apresentar desempenho produtivo inferior à média de todos os porta-enxertos avaliados no experimento. Portanto, esses porta-enxertos também se revelaram como os mais estáveis com base no modelo de Annicchiarico (1992), uma vez que apresentaram as maiores magnitudes para o parâmetro " $\omega_{i}^{\prime}$ ( $\omega_{\text {Maruba/M.9 }}=$ 126,$\left.92 ; \omega_{\text {JM.7 }}=117,48\right)$. Dessa forma, o JM.7 apresentou desempenho equivalente à combinação 'Maruba/M.9', proporcionando rápida indução de início da produção à 'Fuji', altas produtividades (anual e acumulada, e eficiência produtiva) e comportamento produtivo mais estável. Logo, os resultados obtidos sugerem que o 'JM.7' representa uma alternativa a ser utilizada na diversificação de porta-enxertos no sistema pro- dutivo da macieira adotado atualmente no Brasil.

Vale destacar também que o portaenxerto JM.8 evidenciou desempenho produtivo superior ao 'M.9' em duas safras (2006/07 e 2008/09) e maior estabilidade produtiva em relação ao seu genitor $\left(\omega_{\mathrm{JM} .8}=94,37 ; \omega_{\mathrm{M} .9}=71,09\right) .0$ porta-enxerto JM.2, no entanto, foi o menos regular quanto ao desempenho produtivo da 'Fuji' ao longo das safras avaliadas, se equivalendo ao 'M.9', os quais também foram os porta-enxertos menos estáveis $\left(\omega_{\mathrm{JM} .2}=46,11 ; \omega_{\mathrm{M} .9}=\right.$ 71,09).

Já em relação à massa de frutos, foram observadas poucas diferenças entre os diferentes porta-enxertos ao longo das quatro safras analisadas. Contudo, o JM.2 foi o que induziu maior calibre de frutos às plantas de 'Fuji', além de ter sido considerado como o porta-enxerto mais estável $\left(\omega_{\mathrm{JM} .2}=101,67\right)$, embora todos os demais porta-enxertos também tenham apresentado estimativas elevadas do índice de confiança " $\omega_{i}$ ", com magnitudes próximo a 100.

Ao finalizar as avaliações, no momento da erradicação do pomar em questão, foram observadas colônias de pulgão lanígero sobre os porta-enxertos JM.7 e JM.8, que são indicados pela literatura como resistentes a essa praga (Soejima et al., 1998a). Esse comportamento pode estar associado ao clima diferenciado, característico do sul do Brasil, que eventualmente propicia condições mais favoráveis à colonização desses porta-enxertos inicialmente caracterizados como resistentes no Japão, ou em função de alterações na relação praga $x$ hospedeiro, possivelmente causada por variabilidade genética desse inseto-praga. Logo, a realização de fu- 
turas avaliações, a serem conduzidas nas condições de cultivo brasileiras, é indispensável para validar a caracterização dos porta-enxertos JM quanto aos níveis de resistência ao pulgão lanígero e a outras pragas que ocorrem no Brasil.

\section{Conclusões}

Com base na área da seção transversal do caule, o 'JM.1', 'JM.7' e 'JM.8' se equivaleram em vigor ao 'M.9', e o 'JM.2' foi mais vigoroso que 'Marubakaido'/'M.9'.

O 'JM.2' gerou os frutos de maior massa, contudo, com maior tempo para o início da produção da copa, baixos índices produtivos e menor estabilidade.

O JM.7 corresponde a uma alternativa equivalente à combinação 'Marubakaido'/'M.9' para compor novos pomares de macieiras 'Fuji' no Meio-Oeste catarinense, pela rápida indução de início da produção da copa, altas produtividades e comportamento produtivo mais estável.

\section{Agradecimentos}

À Fundação de Amparo à Pesquisa no Estado de Santa Catarina (Fapesc) pelo apoio financeiro.

\section{Referências}

ANNICCHIARICO, P. Cultivar adaptation and recommendation from alfalfa trials in Northern Italy. Journal of Genetics and Breeding, v.46, p.269-278, 1992.

AUTIO, W.R.; ROBINSON, T.L.; BLACK, B.; BRADSHOW, T.; CLINE, J.A.; CRASSWELLER, R.M.; EMBREE, C.G.; HOOVER, E.E.; HOYING, S.A.; IUNGERMAN, K.A.; JOHNSON, R.S.; LANG, G.; PARKER, M.L.; PERRY, R.L.; REIGHARD, G.L.; SCHUPP, J.R.; STASIAK, M.; WARMUND, M.; WOLFE, D. Performance of Fuji and Mclntosh apple trees after 10 years as affected by several dwarf rootstocks in the 1999 NC-140 apple rootstock trial. Journal of the American Pomological Society, v.65, n.2, p.2-20, 2011.

BUS, G.M.; CHAGNÉ, D.; BASSETT, H.C.M.; BOWATTE, D.; CALENGE, F.; CELTON, J.M.; DUREL, C.E.; MALONE, M. T.; PATOCCHI, A.; RANATUNGA, A.C.; RIKKERINK, E. H.
A.; TUSTIN, D.S.; ZHOU, J.; GARDINER, S.E. Genome mapping of three major resistance genes to woolly apple aphid (Eriosoma lanigerum Hausm.). Tree Genetics \& Genomes, v.4., p.233-236, 2008. DOI: 10.1007/s11295007-0103-3.

CRUZ, C.D. GENES - a software package for analysis in experimental statistics and quantitative genetics. Acta Scientiarum. v.35, n.3, p.271-276, 2013. DOI: 10.4025/actasciagron.v35i3.21251

CUMMINS, J.N.; ALDWINCLE, H.S. Breeding Apple Rootstocks. In: JANICK J. (ed.) Plant Breeding Reviews. Westport: Avi Publishing Co., v.1, 1983. p.294-394.

DENARDI, F. Porta-enxertos. In: Epagri (ed.) A Cultura da Macieira. Florianópolis: Epagri, 2002. p.169-227.

DENARDI, F.; KVITSCHAL, M.V.; HAWERROTH, M.C. Porta-enxertos de macieira: passado, presente e futuro. Revista Agropecuária Catarinense, v.28, n.2, p.89-95, 2015. Disponível em: http://publicacoes.epagri.sc.gov. br/ index.php/RAC/article/view/167/76. Acesso em: 31 mar. 2020.

DENARDI, F.; KVITSCHAL, M.V.; HAWERROTH, M.C. Yield performance of apple rootstocks of the Geneva series on replanting soil. Pesquisa Agropecuária Brasileira, v.53, n.8, p.924-933, 2018. DOI: 10.1590/s0100$204 \times 2018000800007$.

DENARDI, F.; KVITSCHAL, M.V.; SCHUH, F.S.; MANENTI, D.C. Efeito de porta-enxertos na indução da brotação da copa das macieiras 'Gala' e 'Fuji'. Revista Agropecuária Catarinense, v.26, n.2, p.61-63, 2013. Disponível em: http://publicacoes.epagri.sc.gov.br/index.php/RAC/article/view/609/511. Acesso em: 02 abr. 2020.

DENARDI, F.; SPENGLER, M.M. Comportamento da cultivar de macieira Fuji (Malus domestica, Borkh.) sobre três diferentes porta-enxertos. Revista Brasileira de Fruticultura, v.23, n.3, p.630-633, 2001. DOI: 10.1590/ s0100-29452001000300037.

EBERT, A.; PETRI, J.L.; BENDER, R.J., BRAGA, H.J. First experiences with chill units models in Southern Brazil. Acta Horticulturae, v.184, p.89-96, 1986.

KÜDELA, V.; KREJZAR, V.; KUNDU, J.K.; PÁN-
DOVÁ, I.; ACKERMANN, P. Apple burrknots involved in trunk canker initiation and dying of young trees. Plant Protection Science, v.45, p.1-11, 2009.

PASA, M.S.; BRIGHENTI, A.F.; KATSURAYAMA, J.M.; SILVA, C.P.; CIOTTA, M.N.; CARRA, B. Productive performance of 'Fuji' apple trees on 'JM' series rootstocks, in São Joaquim/ SC. Revista Brasileira de Fruticultura, v.39, n.Spe., (e-403), 2017. DOI: 10.1590/010029452017090.

PASA, M.S.; KATSURAYAMA, J.M.; BRIGHENTI, A.F.; ARAUJO FILHO, J.V.; BONETI, J.I.S. Desempenho de macieiras 'Imperial Gala' e 'Fuji Mishima' em diferentes porta-enxertos. Pesquisa Agropecuária Brasileira, v.51, n.1, p.17-26, 2016. DOI: 10.1590/S0100204X2016000100003.

ROBINSON, T.L.; FAZIO, G. Performance of Geneva rootstocks in on-farm trials in New York. Acta Horticulture, n.903, p. 249-256, 2011. DOI: 10.17660/ActaHortic.2011.903.31.

ROBINSON, T.L.; FAZIO, G.; HOYING, S.; MIRANDA, M.; IUNGERMAN, K. Geneva" Rootstocks for Weak Growing Scion Cultivars Like 'Honeycrisp'. New York Fruit Quarterly, v.19, n.2, p.10-15, 2011. Disponível em: http:// nyshs.org/wp-content/uploads/2016/10/2. Geneva-Rootstocks-for-Weak-GrowingScion-Cultivars-Like-Honeycrisp.pdf. Acesso em: 20 mar. 2020.

RUSSO, N.L.; ROBINSON, T.L.; FAZIO, G.; ALDWINCKLE, H.S. Field evaluation of 64 apple rootstocks for orchard performance and fire blight resistance. HortScience, v.42, n.7, p.1517-1525, 2007. Doi: 10.21273/ HORTSCI.42.7.1517.

SOEJIMA, J.; BESSHO, H.; KOMORI, S.; TSUCHIYA, S. New apple rootstocks ARM.1, ARM.7 and ARM.8. Acta Horticulturae, v.484, p.217-220, 1998a.

SOEJIMA, J.; BESSHO, H.; TSUCHIYA, S.; KOMORI, S.; ABE, K.; KOTODA, N. Breeding of Fuji apples and performance on JM rootstocks. Compact Fruit Tree, v.31, p.1-9, 1998b.

WEBSTER, T. Dwarfing rootstocks: past, present and future. The Compact Fruit Tree, v.35, n.3, p.67-72, 2002 . 